Article

\title{
Should Postponing Motherhood via "Social Freezing" Be Legally Banned? An Ethical Analysis
}

\author{
Stephanie Bernstein * and Claudia Wiesemann \\ Department of Medical Ethics and History of Medicine, University Medical Center Goettingen, \\ Humboldtallee 36, Goettingen 37073, Germany; E-Mail: cwiesem@gwdg.de \\ * Author to whom correspondence should be addressed; E-Mail: sbernst@gwdg.de; \\ Tel.: +49-551-39-9009; Fax: +49-551-39-9554.
}

Received: 13 March 2014; in revised form: 30 April 2014 / Accepted: 28 May 2014 /

Published: 5 June 2014

\begin{abstract}
In industrial societies, women increasingly postpone motherhood. While men do not fear a loss of fertility with age, women face the biological boundary of menopause. The freezing of unfertilized eggs can overcome this biological barrier. Due to technical improvements in vitrification, so-called "social freezing" (SF) for healthy women is likely to develop into clinical routine. Controversial ethical debates focus on the risks of the technique for mother and child, the scope of reproductive autonomy, and the medicalization of reproduction. Some criticize the use of the technique in healthy women in general, while others support a legally defined maximum age for women at the time of an embryo transfer after oocyte cryopreservation. Since this represents a serious encroachment on the reproductive autonomy of the affected women, the reasons for and against must be carefully examined. We analyze arguments for and against SF from a gendered ethical perspective. We show that the risk of the cryopreservation of oocytes for mother and future child is minimal and that the autonomy of the women involved is not compromised. The negative ethical evaluation of postponed motherhood is partly due to a biased approach highlighting only the medical risks for the female body without recognizing the potential positive effects for the women involved. In critical accounts, age is associated in an undifferentiated way with morbidity and psychological instability and is thus used in a discriminatory way. We come to the conclusion that age as a predictor of risk in the debate about SF is, from an ethical point of view, an empty concept based on gender stereotypes and discriminatory connotations of aging. A ban on postponing motherhood via SF is not justified.
\end{abstract}


Keywords: postponed motherhood; egg freezing; reproductive autonomy; ethics; gender

\section{Introduction}

In most industrial societies, people postpone their decision to have children to later in life [1,2] ${ }^{1}$. While it is unproblematic for men to still have a biological child at an advanced age, women face biological limits due to the time span of female fertility. These biological limits weigh even more heavily at a time of demographic change. Life expectancy is constantly increasing. Nowadays, an average European woman lives almost twice as long as a century ago $[3,4]$. It was long considered to be a woman's fate not to be able to conceive and bear genetic children of her own from the age of 45 . However, technological advancements in reproductive medicine make it possible to prolong this time span of fertility. Young women can have their eggs frozen in order to have them fertilized, and thus fulfill their desire to have a child, at a later point in time, if necessary even after menopause.

The technique of egg freezing initially served to afford women receiving gonadotoxic therapy ${ }^{2}$ an opportunity to fulfill their desire to have a child in spite of chemotherapy and toxic damage to their ovaries. However, this technique initially yielded low success rates due to the high water content in unfertilized eggs [5]. Now that the success rates have in the meantime been improved [6,7], practitioners of reproductive medicine are increasingly offering this option to fertile and healthy women as well. The use of this procedure in the case of fertile women who want to secure the option of having a child at a later time in life has been labelled "social freezing" (SF). What might be hailed as making strides toward gender equality has actually generated a widespread sense of unease. Criticism has been sparked by cases in which older women, some even over 60, have given birth to a child after an egg donation. Critics have voiced objections against the technique of SF as well on similar grounds. Some of them criticize the use of the technique in healthy women in general, while others support a legally defined maximum age for women at the time of an embryo transfer ${ }^{3}$. For, in many countries, including Germany, there is not yet any legally binding age limit for the use of this technique. In Denmark, by contrast, there is a direct prohibition on technically assisted reproduction for women of 45 and older ([8], No. 923 2006, chap. 2, § 6). The law stipulates a maximum storage period for frozen eggs of five years ([8], chap. $3, \S 15$ ).

This represents a serious encroachment on the reproductive autonomy of the affected women. The reasons for and against a legally specified age limit for egg-cell transfer for the purpose of bringing

1 This research was funded by VolkswagenStiftung, Germany, as part of the research group "Autonomy and Trust in Modern Medicine".

2 Several conditions such as cancer or autoimmune diseases require gonadotoxic therapy. Another reason for opting for SF can be the legal situation in the respective country, e.g., if embryo cryopreservation is prohibited by law as in Italy (e.g., by the Italian law on medically assisted reproduction (Law 40/2004)).

3 In 2011, we conducted a questionnaire survey "On the ethical aspects of the cryopreservation of unfertilized oocytes" among fertility physicians. $51 \%$ of respondents were in favor of a legal regulation of "social freezing". Of the $51 \%$ who spoke out in favor of legal regulation, a majority (55\%) chose "maximum age at the time of implantation" as the matter to be regulated. This means that $28 \%$ of all of those we surveyed were in favor of an age limit for "social freezing". 
about a pregnancy must therefore be carefully examined. Frequently cited arguments refer to the safety of the procedure for the woman and the child to be born. The benefits and risks of SF for the child to be born as well as for the woman, should she become pregnant at an advanced age, are discussed. Another point of discussion is the woman's autonomy. Are women able to make an autonomous decision in favor of SF, or are they exposed to social pressures that undermine their freedom? Many critical authors adopt a gender perspective in this connection - that is, they also consider SF under the aspect of the social position of women in society and criticize implicit and explicit mechanisms of oppression. They arrive at the seemingly paradoxical conclusion that women's emancipation is promoted by placing restrictions on the individual freedom to avail of SF. The aim of our paper is to examine the cogency of this line of argument.

The SF technique is made possible by the long-term cryopreservation of oocytes. Following hormone stimulation, eggs are retrieved from young women, frozen, and stored in liquid nitrogen. Additional protective substances, so-called cryoprotectants, are used to prevent freezing damage. The freezing methods currently in use, slow freezing and vitrification ${ }^{4}$, differ in the speed at which the temperature is lowered and in the amounts and kind of cryoprotectants used. After thawing, fertilization can occur with the aid of in vitro fertilization (IVF) via the intracytoplasmic injection of sperm into the egg (ICSI). Survival and implantation rates of the once frozen eggs after thawing and insemination show that these techniques are effective and successful freezing procedures [9-13]. Egg cells can be frozen in a fertilized state (inseminated oocyte) or an unfertilized state (mature oocyte ${ }^{5}$ ). Embryos can be cryopreserved as well. Unless otherwise specified, in what follows we use the terms oocyte, egg, or egg cell to refer to the freezing of unfertilized mature oocytes.

\section{Arguments and Criticism}

\subsection{Arguments over Benefits and Risks}

\subsubsection{Risks of Egg Retrieval and Cryopreservation Techniques}

The assessment of the risks of the technique plays a central role in the discussion over "social freezing". Karey Harwood criticizes the fact that there are insufficient data on the safety of the procedure. Others point out that the long-term effects of egg retrieval for women cannot be estimated and that risk-benefit analyses are not possible $[15,16]$. In so arguing, they imply that it is scarcely possible to make assertions about the risks associated with the procedure of "social freezing". However, this does not correspond to the data available, as we will show in what follows.

Nowadays, hormonal stimulation with ensuing egg collection prior to the freezing process can be conducted with a very low risk of less than one percent for complications such as bleeding or ovarian

4 Slow freezing is a freezing process in which cells are cooled at a rate of $1{ }^{\circ} \mathrm{C} / 1.8^{\circ} \mathrm{F}$ per minute. Vitrification requires a rapid reduction in temperature. During the process, fluid is withdrawn from the cell by cryoprotectants. The cell content and the remainder of the cell fluid go into a firm viscous aggregate state. This process requires larger amounts of cryoprotectants.

5 Immature eggs can likewise be frozen and subsequently ripen in vitro. Research is currently being conducted on this method. To date, convincing results are yet to be achieved (e.g., [14]). 
hyperstimulation syndrome (OHSS) [17]. The risks directly associated with egg retrieval are very slight. According to the current state of science, there is only a slight risk of damage to the woman's body through egg retrieval and the associated preparation.

Further sources of concern regarding the safety of the process are freezing damage and the toxicity of cryoprotective agents (CPA). Potentially affected by freezing damage are, in particular, the spindle apparatus and the associated arrangement of chromosomes [18,19]. However, the spindle apparatus recovers after thawing and seems to do so without alterations in $>80 \%$ of the cases $[18,20]$. The older the woman is at the time the cells are frozen, however, the greater the damage to the spindle apparatus after thawing [18,21]. Although higher concentrations of cryoprotectants are used in vitrification than in slow freezing procedures, vitrification causes less damage to the oocytes. Better rates of oocyte development and survival are achieved than in the case of slow freezing procedures by oocyte vitrification [9,22]. Several studies reported no statistically significant differences in fertilization and implantation rates between oocyte vitrification and fresh oocyte insemination cycles [6,7,13,23,24]. Some studies showed lower fertilization rates after vitrification of oocytes (e.g., [25]).

The toxicity of cryoprotectant substances is a complex issue, given the fact that not only concentration but also temperature and time of exposure are crucial for resulting toxicity for the cells [26]. While the toxicity of cryoprotectants after egg vitrification has been intensively studied in mammalian oocytes, studies on human eggs are scarce [27]. Recent analyses of the ultrastructure of human oocytes seem to indicate that the damage caused by freezing procedures and cryoprotectants is low ${ }^{6}$ and that the overall ultrastructural appearance of mature oocytes is good [27]. However, it has to be stated that this study design gives limited information about the possible loss of function and DNA damage. Recent studies focus on morphological and functional analysis of the egg and the resulting embryo. Forman et al. studied possible DNA damage in embryos after the vitrification of oocytes and found no increased risk of embryonic aneuploidy [25]. Mitochondrial and microtubular functioning differed depending on the combination of CPA used [28]. Further research is needed in order to minimize damage [9]. The current state of research suggests that the toxicity of freezing substances is not alarming, assuming that the optimal substances are used in the optimal concentrations [28-30]. There is a possibility of the material becoming contaminated during storage in liquid nitrogen. However, such an event has not yet been described in the case of human oocytes or embryos ([27], p. 38).

All cryoprotectants have been used for some time in medicine and many are used in slow freezing procedures. They are used in lower concentrations but for a longer period of time due to slower cooling processes, so that in the end a similar concentration of cryoprotectants in the oocyte is achieved $[22,26]$. The woman's age at the time the cells are frozen seems to have the greatest influence on the harmful effects of cryoprotectants in the vitrification process [18,21]. The risk of contamination during storage is slight [31].

A primary focus of concern is the impacts of the freezing procedure on the child. The American Society for Reproductive Medicine (ASRM) warns in two separate communiqués about the unforeseeable risks of chromosomal abnormalities and malformations of the child as a result of the

6 Alterations of the cell relate to a vacuolization of the cytoplasm and a hardening of the zona pellucida (the surrounding membrane of the cytoplasm) [27]. 
vitrification of oocytes [32,33]. According to currently available data, however, there is little reason to speak of alarmingly high risks of this kind [34-37]. A review of the outcome of children born following the vitrification of eggs does not describe any increased rates for chromosomal abnormalities or malformations [34]. In a meta-analysis of over 900 children born after vitrification and slow freezing processes, the malformation rate is $1.3 \%$ [36]; in another study involving over 200 neonates not included in the meta-analysis by Noyes, the rate is $2.5 \%$ [37]. This means that the results are all within the scope of the malformation rate in the case of spontaneous births, which is around 3\% [38]. Only one study by Belva et al. describes a rate of malformations in the group of cryopreserved embryos $(6.4 \%, \mathrm{~N}=937)$ that is twice as high as the control group $(3.2 \%, \mathrm{~N}=5719)$ [39].

There is an urgent need of further prospective case control studies with comparable values and a high number of cases in the comparison and control groups. However, recent studies by no means support alarming inferences concerning unforeseeable risks. On the contrary, the current state of research seems to confirm that the events feared by the ASRM are not empirically confirmable. Notably, in a recent guideline on the cryopreservation of oocytes, the ASRM concludes that the procedure is no longer experimental and that the data on outcomes can now be considered fairly satisfactory [40].

\subsubsection{Risks of a Late Pregnancy}

The effects of wanting to fulfill one's desire for a child also later in life are discussed under the topic of late motherhood ${ }^{7}$. Medical, psychological, demographic, and moral perspectives are brought to bear on these effects. In what follows, we will refer only to the ethically relevant arguments in the discussion about SF.

Late motherhood is not a clearly defined concept. Medically speaking, pregnancies of women of 35 and older are considered to be high-risk pregnancies ([41], p. 53). It is unclear whether pregnancies after menopause are also counted among late pregnancies or whether they form a separate complex. This also depends on whether specific risks can be identified that only apply to the group of postmenopausal pregnancies. Late motherhood involves higher risks (e.g., [42-48]). According to Kenny et al., the risks increase continually with increasing age, so that it cannot be assumed that there is an exponential increase in risk beyond a certain age ${ }^{8}$ [46]. In most studies on late pregnancies, the risk factors of high blood pressure, gestational diabetes, and preeclampsia are sharply elevated and generally occur in between 10 and $20 \%$ of cases (e.g., [49]). There are also studies that show a strongly increased rate of cesarean section in women aged 40 and older [50-52]. The chief risks for the newborn child are prematurity and low birth weight [47]. High maternal age is identified as an independent and direct risk factor for complications during pregnancy [42,47]. According to Sauer,

7 The effects should actually be dealt with under the topic of late parenthood. Since SF relates to women and the criticism is based on aspects of late motherhood, we concentrate on these points of criticism. Beyond this, however, there is need of a critical discussion from the perspective of gender.

8 This point is important because it complicates the stipulation of a specific upper age limit. Another important aspect to be mentioned is that the differing age categories and age ranges within medical studies as well as the probably differing risks after natural conception, egg donation or SF make a clear analysis of the risks involved in late pregnancy difficult. 
however, it is questionable whether there is a linear relationship between age and elevated risk: "It is often difficult to determine if the observed increase is due to age alone or to other confounding variables such as pre-existing disease, obesity, parity and socio-economic factors" [53]. The specific reason frequently cited for regarding age as an independent risk factor is the increase in the frequency of stillbirths with higher maternal age [54-57]. It is true that, after correcting for potential confounders such as pre-existing conditions, the probability of a stillbirth in women of 40 and older compared to women between 35 and 39 rises from $0.9 \%-1.5 \%$ (see the diagram in [54]). In a systematic review on stillbirth and maternal age, the authors arrive at a similar conclusion, namely that a stillbirth occurs in about $1 \%$ of cases of older women in developed countries [56]. These figures point to a statistically significant, but by no means dramatic increase. The underlying pre-existing conditions as well as general physical health, possibly influenced by excessive nicotine use or obesity, seem to be more significant predictors of complications in pregnancy than chronological age. What is more, it is striking that protective factors are rarely mentioned in the discussion of late pregnancy. High socio-economic status is correlated with a significant reduction in the risk of preterm births in the case of older women ([58], p. 42). Only holistic studies, such as those that already exist on age mortality, could help to distinguish more precisely the effects of specific risk factors and the underlying causes ([58], p. 39). Studies on the risks of higher paternal age for pregnancy and childbirth are similarly underrepresented in medical research. A PubMed search conducted in January 2014 with the keyword "late motherhood" yielded 109 results as compared to 17 results for the keyword "late fatherhood" " . These partial results create the false impression that late pregnancy is an event that can be positively or negatively influenced by the woman alone, focused on the age of the woman and disconnected from socio-economic and psychological factors.

The debate over SF also addresses the ability of late mothers to cope with physical and psychological stress. Shkedi-Rafid and Hashiloni-Dolev ask: "will the mother be able to fulfil her maternal role as the years go by? Will she not be less energetic than a young mother?" [59]. Whether older parents are mentally and physically able to take care of their child is also discussed in the debate over postmenopausal egg donation (e.g., [60-62]). Some authors question the psychological stability of older mothers [60]. Physical ailments, as well as the feeling of frailty, increase with age. Nevertheless, older mothers have many resources, such as partnership and economic security that constitute a favorable living situation for late motherhood [63]. Age also has positive effects on parenthood. Children of older mothers (older than 35 years) are more likely to be born into a stable family environment. The families are often financially secure and partners are more likely to be involved in the care and upbringing of the child [64]. A study on late motherhood and parental stress showed that levels of stress were even lower in the group of women over 50 than in the group of 40-year-olds [65]. Goold and Savulescu thus conclude that "there are reasons to think it is actually better for women to have children later in life" ([66], p. 54) Considering the risks of parenthood only

9 PubMed search on 22 January 2014. Other search combinations ([advanced age], [postponed] AND [motherhood], [advanced age], [postponed] AND [fatherhood]) yielded similar proportions among the results, albeit at a very low number of articles (max. 7). MeSH terms on this topic could not be identified. 
with regard to general physical condition seems one-dimensional and does not do justice to the variety of resources that can actually have a positive influence on parenthood.

\subsubsection{Benefits of SF}

Critics of SF not only invoke the risks of the technology but also doubt its usefulness both for individual women and for women as such. Karey Harwood argues that it is to be feared that eggs would undergo further aging due to the freezing process and that, as a consequence, one cannot predict what birth rates will be achieved with the technique, especially when eggs are collected from women over the age of 35. She speaks in this context of a potential twofold disadvantage that women would risk if they were to have their egg cells frozen, namely, the freezing of eggs at a time of life when the quality of these cells is poorer, and the further loss in quality due to the process of freezing and thawing [67]. Other authors likewise point out that the success of the technique cannot be promised with certainty since even IVF without SF leads to conception and the birth of a child only in a maximum of $30 \%$ of cases [16]. Finally, there are doubts concerning the benefits for women as such. It is argued that the technique entices women to postpone their desire to reproduce to an older age, but one at which, statistically speaking, the probability of becoming pregnant declines sharply [59]. Moreover, the technical solution is inadequate, it is argued, since it is a social problem when healthy young women do not feel in a position to have a child [65]. These women should be afforded greater opportunities to reconcile family and career, and discrimination against women of childbearing age should be combatted.

Against these arguments it must be objected that it has not been possible to demonstrate cell aging or damage caused by the length of storage in the case of vitrified embryos [68]. On the contrary, the earlier an egg is frozen, the lower the risks of aneuploidy or chromosomal aberrations ${ }^{10}[69,70]$. The reproduction physicians Sauer, Paulson, and Lobo note: "the decreasing fecundity normally seen in older women is primarily due to ovarian rather than uterine factors" [53]. Thus, reproductive success depends on the age of the egg, not on the age of the uterus. Even if studies of age effects on the uterine function show a decreasing uterine capacity to adopt to and manage the gestational changes that are mostly explained by an impaired myometrial function and impaired decidual and placental development at later age, it remains unclear how severe these decreases are [71]. The British medical scientists Nelson, Telfer, and Anderson also describe probable compensatory mechanisms of uterine aging that consist of higher placental weight in older women compared to younger women [71]. The examples of pregnancies through egg donation in women over 50 show that uterine incompetence does not impede pregnancies with healthy outcomes for woman and child $[52,72,73]$.

Were the freezing of eggs to be offered to women over 35 , the success rates would indeed suffer as a result. Harwood highlights this important fact with her critique of the twofold disadvantage. However, the actual target group for SF is younger women. The fact that the average age of women opting for SF is currently 38 is not evidence that poor success rates are achieved with the procedure in principle, but is instead an argument for improved social information and education concerning the

10 Aneuploidy means that the number of chromosomes in a cell deviates from the usual distribution of chromosomes. Chromosomal aberration refers to a change in the structure of the chromosome due to mutated, missing, or extra DNA. 
procedure [74]. Moreover, most women — assuming that they have been appropriately informed about the procedure - will not be so naïve as to consider a future pregnancy as guaranteed. This is also the assessment of the fertility physicians Eli Rybak and Harry Lieman: "We feel that there is no basis to assume patients cannot understand that elective oocyte cryopreservation increases, but does not guarantee, their chance of autologous procreation" [75].

Even today, there is no guarantee of becoming pregnant either by natural means or by means of reproductive medical techniques. The natural conception rate per cycle among young women is between 20 and $25 \%$. Therefore, it is extremely unlikely that women will rely entirely on the success of SF and subsequent transfer. Even lower success rates would not speak against a technique. The low rate of conception following IVF in some cases is well known and has not deterred women in the meantime, for the past 30 years, from availing of this technology ${ }^{11}$. Approximately the same success rates apply to IVF cycles with fresh oocytes and with oocytes thawed after vitrification, as studies show $[6,7,13]$. Admittedly, it must be borne in mind here that an existing infertility is treated in the case of IVF without SF, whereas in the case of IVF following SF a woman who is in principle fertile is postponing a pregnancy to a more advanced age. Because of the IVF that then becomes necessary, she is less likely to become pregnant than by natural means at a younger age. However, it does not necessarily follow from the fact that women have their eggs frozen as a precaution that they will refrain entirely from having a child at a younger age. On the contrary, it is conceivable that women will keep other options open in addition to SF, presumably depending on a range of other factors that can be influenced but not predicted. These include, for example, whether they meet a suitable partner or whether their job situation becomes more stable. Finally, the assertion that SF is a technical pseudo-solution to a social problem rests on two questionable premises. First, it presupposes that the availability of SF will entail that other measures to promote the compatibility of career and family will be restricted or fail to be taken altogether. It is hard to render such a linkage plausible. Even when women have children later in life, they will still need structural support to combine their job and childcare. Besides, as gender roles change, men will claim a better compatibility of job and family as well. Those who assert that SF is a technical pseudo-solution to a social problem presuppose that, in a society in which genuine equality had been realized, all women would want to have their children at a young age. However, this is not plausible either, since presumably even under such optimal conditions some women - as now already many men - would want to postpone having children to a time when they have already made important career moves or their life situation seems compatible with starting a family. Below we will show in addition that reproduction at a younger age instead of at a relatively advanced age is not invariably better for health reasons, either for the woman or for the child. Thus, the critics of SF cannot bring a compelling argument against the utility of the technique.

11 Success rates of IVF depend mostly upon the age of the woman at the time of hormonal stimulation and/or egg retrieval. The quality of the egg decreases significantly with increasing age [68,69]. For 2012, the HFEA reports a live birth rate per IVF cycle (a transferred fresh embryo) between 41.5\% for women aged 18-34 and 3.4\% for women aged 45 and older ([76], p. 26). 


\subsection{Autonomy}

Women's autonomy is a frequently cited argument in the discussion. Proponents of SF regard respect for autonomous decisions as a weighty moral reason in support of the procedure [77,78]. Critics, by contrast, doubt whether the decision is self-determined. The criticism is put forward in two different forms. Authors either appeal to relational approaches to autonomy and thus situate the motives for opting for SF within a wider social context, or they evaluate the individual decision directly. In what follows, we address the two lines of argument in turn.

An essential point of reference of the notion of relational autonomy is that people should be perceived in their social context. Social interactions shape the self-understanding and identity of persons. Political, cultural, and sociocultural influences can either enable or restrict autonomy. This influence should be analyzed and taken into account in conceptions of autonomy. Based on these considerations, Carolyn McLeod and Susan Sherwin derive a political responsibility to promote change at the social level: "Insofar as oppression has reduced or undermined an agent's ability to act autonomously in various contexts, relational autonomy seeks politically aware solutions that endeavor to change social conditions and not just expand the options offered to agents" ([66], p. 260). Not a few critics of SF are alert to the danger of only expanding options without changing social conditions. Shiri Shkedi-Rafid and Yael Hashiloni-Dolev point out that social pressures would constrain women to decide in favor of SF. The social pressure to compete on the labor market, they argue, now already compels many women to put their careers before the fulfillment of their desire to have children. The widespread use of the vitrification of oocytes would increase the pressure on women to postpone their desire to have children and thus reduce the likelihood of their fulfilling it [59].

Were employers and government to attach less importance to the compatibility of occupation and family as a result, these would in fact be disturbing developments. However, this trend is, as already described above, unlikely. The responsibility of society to facilitate different life plans is not less as a result. The situation in the labor market is in any case not necessarily the only reason why women opt for SF. Women could also decide to have a child later in life for reasons that have nothing to do with this, for example, because they have a longer life expectancy or because their lives have become centered in a particular place only later in life. Proponents of a relational concept of autonomy should devote just as much attention to the social pressures on women to have a child early in life. The option to have children later in life is instead an opportunity to reflect upon the gendered role of woman and mother and thus to emancipate oneself from social constraints. At any rate, the relationship between social constraint and the use of SF is not as straightforward as Harwood or Shkedi-Rafid and Hashiloni-Dolev imagine.

Angel Petropanagos also appeals to the concept of relational autonomy. She asks whether the woman's decision in favor of SF can be regarded as free at all and whether it is not rather a function of a complex system of personal, social, and political factors. "A relational approach to autonomy requires one to understand the personal, social and political factors that shape women's reproductive choice" [79]. A range of factors not open to influence such as the lack of a suitable partner and diminishing fecundity, she argues, leave women with little or no choice but to secure their fertility for 
a later date. The decision in favor of SF, therefore, is not a genuine reproductive "choice" 12 . Petropanagos's analysis is important because it highlights the fact that planned life contents can often be thwarted by unexpected events and are often shaped by social and political factors. However, even if this is undoubtedly true, the individual decision may very well be self-determined. We have to consider the complexity of differentiating between 'circumstance' and 'choice'. What is considered to be an either/or category in theory will often overlap in people's own description of their childlessness [81]. Circumstances such as a suitable partnership, career options, friends, and other fulfilling interests are not only factors independent of the individual's choice or influence, but may in fact be part of the individual's own choices. Several studies indicate that the proportion of women who deliberately remain childless has increased, even if the overall percentage of these women is small $[81,82]$. Although motherhood is in fact still very strongly socially normalized [83], the view of not having a choice at all seems rather implausible in the light of the increasing diversity of life and family designs. Therefore, Petropanagos is in danger of regarding women as playthings of their circumstances and hence of denying them the capacity to make an autonomous decision.

Some authors also take a critical view of the individual motivation of the affected women. Some critics of SF address the reasons that could lead to a decision in favor of SF. In doing so, they ascribe specific psychological behavioral patterns to women. Reasons for considering SF would be, for example, the "evasion of a decision" ([16], p. 36) or the "repression of finitude, frustration, and inability to cope with the demands of life" ([84], pp. 246-47). Thus, assuming that women are not pressed into making their decision by social constraints (so that they cannot be attributed any responsibility for their decision), then they opt for SF for the "wrong reasons". By contrast, Bittner, Müller, and Bozzaro advocate other values, such as fulfilling one's desire to have children as early as possible, natural reproduction, according priority to one's desire to have children over other contents of life, or the correlation of certain life events with certain phases of life. People who do not decide in accordance with this scale of values, they argue, act for the wrong reasons or have not adequately confronted their desire to have children. However, this involves a confusion of autonomy with orthonomy-orthonomy meaning that, for the sake of good governance, individuals have to comply with common values irrespective of their self-determined choice. The philosopher Paul Benson criticizes such strongly substantive concepts of autonomy because "they conflate the power to take ownership of one's action with something quite different, the power to get things right, or the ability to adopt the preferences or values one ought to have" ([85], p. 132). Some values may appear correct to certain people as personal criteria and justify why they would like to have a baby sooner. However,

12 In the article cited, Angel Petropanagos analyzes whether there is a moral difference between disease-related egg freezing and age-related egg freezing (which we refer to here as SF). In her doctoral thesis, she gives a comprehensive moral analysis of SF. She concludes that an upper age limit for access to reproductive technologies is morally appropriate because women would otherwise be in danger of "ageist discrimination by inclusion", meaning that women would feel under pressure to bear a child even later in life ([80], p. 143). The reasons for an upper age limit are possible harms to the woman, the resulting offspring, and others in society, especially other women ([80], p. 142). She also doubts that the decision of older women to opt for risky procedures of reproductive technologies is an autonomous choice of their own. She mentions internalized oppressive social norms, pronatalist and ageist values in particular, as the main reasons for this lack of autonomy ([80], pp. 146, 165). 
these values definitely cannot serve as criteria for all people who want to have children, for the "right" kind of autonomy, or even for the ethical evaluation of a procedure in reproductive medicine. Bittner, Müller, and Bozzaro implicitly encourage a stereotypical conception of women. This represents women as agents who respond incompetently, evasively, and in emotionally immature ways to their life situation. The woman is perceived as a counterpart to the rationally planning and less emotional man, which corresponds to the classical stereotypes of male and female behavior ([83], pp. 16-20). However, the authors provide no evidence that this is how women actually reach the decision to freeze their oocytes.

Moreover, Bittner and Müller complain that women would initially postpone their desire to have children, and later, having lived a fulfilled life, would still have a child under the "solipsistic paradigm" ([16], p. 39): "It might seem implausible if a woman of 60 suddenly wants to integrate children into her life on the grounds that only a life with children is fulfilled and happy. If you have led your life for 60 years against the backdrop of a 'solipsistic paradigm', you have to ask yourself why this should change with 60 - and how authentic such a change is within the context of a coherent life."

This conception rests on strong assumptions: (1) that the conduct of life is coherent; and (2) that it is fundamentally morally questionable to postpone the desire to have children to later in life. That the first assumption is not necessarily true was already mentioned in the previous section. One's life plan does not invariably correspond with the actual course of life. Unforeseen events and political or economic constraints can alter the actually envisaged plan. The assumption that life events should be correlated with specific phases of life is primarily a piece of descriptive knowledge. One cannot make direct normative inferences from this finding that could count as moral objections against late motherhood. The assumption of a solipsistic lifestyle also involves stereotypical images of women. In a dichotomous representation of women, the warm, altruistic, considerate mother is contrasted with the calculating, egoistic career woman who represses her desire to have children. However, other inferences can be drawn from a survey of 1049 women on their motivations for opting for or against SF [86]. Women who considered SF differ from those who rejected the procedure neither in education, occupation, nor income bracket. This refutes the assumption that women would want to take advantage of SF for egoistic or career-oriented reasons. A strong desire to have children and the acceptance of becoming pregnant even at a more advanced age are cited as the most important factors influencing a potential decision to avail of the procedure [86]. In this respect, the image of the career-driven woman seems to be a prejudice based on the underlying assumption that women with career ambitions could not have any desire to have children or only one that is "distorted". This way of viewing things involves the danger of degrading the desire to have children of such women and of stigmatizing those who nevertheless give expression to this desire. Men accommodate themselves to the labor market and to concepts of professional development just as much by having children later in life. Moreover, men postpone their desire for children to an even later time in life than women [87]. Through a one-sided view, women's behavior is pathologized instead of being regarded as a constructive response to transformation processes at all levels of society.

It follows from the foregoing remarks that the assumption that women decide to have their eggs frozen out of sheer compulsion or out of a lack of self-determination and self-reflection is implausible, although it must be acknowledged that social and economic circumstances in particular influence the decision. 


\section{Conclusions}

In our paper, we have examined whether it is ethically justified to prohibit SF in principle, or at least for women above a certain age limit. We have critically examined empirical data and ethical arguments for and against SF. We inquired into the risk and benefits of the technique for the mother and the child. We also addressed whether women's capacity for self-determination is compromised by social factors and whether SF is the wrong technological answer to what is in fact a social problem. With regard to SF, is it true that, as Karey Harwood holds, "technological solutions to social problems are inadequate and often result in the further oppression of disadvantaged groups" [67]?

Our study has shown that existing data indicate that the process does not entail any significant increase in the risk of a malformation in the child. It also follows from our evaluation that even though the risk of morbidity and mortality in a later pregnancy is increased for the woman, the level of interindividual differences is large. However, further follow-up studies are needed. Yet, as Mertes and Pennings rightly summarize, the procedure of SF itself does not represent a significant danger. The danger is instead that women learn too late of its existence and that as a result their eggs are already aged at the time of freezing [74]. Instead, as Goold and Savulescu stress, the positive aspects of late motherhood like equal participation by women in employment, more time to choose a partner, better financial opportunities for the child and a reduction of genetic risks have to be taken into account [78].

Against the self-determined decision of women in favor of SF, it is argued that women are pressed into making the decision by social conditions and hence are not in a position to decide autonomously. However, even if social expectations attached to the woman's role play a contributory role in the decision to opt for SF, this is not sufficient to justify a paternalistic prohibition of the technology. Reproductive decisions are not generally taken in a vacuum, but are specifically characterized by the fact that they situate the person concerned in a social context shaped by traditions and expectations. This holds true for women and men alike. The resulting social pressure should not be counteracted by restricting the scope for making decisions. Instead, the decision for or against this technique should be facilitated through information. Anyone who asserts that this technique unnecessarily medicalizes reproduction would have to explain what is intrinsically bad about availing of SF. For the points of criticism adduced in this context concerning elevated risk or meagre utility are not so emphatic that they alone could justify a general prohibition. In a pervasively technologized world, the ideal of natural reproduction can count at best as a personal preference, but not as a moral principle valid for everyone ([88], p. 146).

Critics of SF have argued further that women would postpone having children for selfish reasons and that postponing childbirth represses the fact of the finitude of human life [16,85]. However, this is a sweeping judgment associated with a stereotypical denigration of women's motives. According to empirical findings, women who fulfill their desire to have children at a relatively advanced age are not a homogeneous group and act on different motives. Though, even an egoistic decision is not per se reprehensible on ethical grounds as long others are not harmed as a result. The desire to procreate and to have a biological child of one's own is a potentially important element of individual conceptions of life and should be recognized as such.

Thus far, therefore, no cogent arguments have been put forward for a fundamental prohibition of SF. So, are there sufficient reasons for a legally stipulated limit on the age of the woman at the time of 
the implantation of the embryo in order to prevent women from using this technique at an advanced age? Late pregnancy is in fact associated with increased risks for the woman. However, these vary between individuals and are not generally higher than in the case of other medical interventions in which people are considered to be capable of making an informed decision, such as a sterilization operation. Another reason to limit the age of women would be the risk for the child to be orphaned at a young age [59-61]. This argument from the debate about postmenopausal motherhood has some merit ([89], p. 33). However, as Goold puts it: "If we really thought that having one older parent was problematic, ageing men conceiving children with younger women would have received greater censure" ([89], p. 34). Age limits for the reproduction of either men or women should comply with the requirements of justice and reproductive equality. For both men and women, conditions like having a younger partner should be taken into account. This would encourage a case-by-case decision rather than a fixed age limit as Goold in fact proposes ([89], p. 34).

In the debate over late motherhood, a particularly critical view is taken of the risks for the woman and the child. Comparable risks for the child that may result from the advanced age of the father at the time of conception, by contrast, seldom receive mention (e.g., $[90,91])$ and at any rate are not grounds for a prohibition on late fatherhood. In any case, the proven protective and generally positive aspects of late parenthood should not be overlooked. For little can be deduced from chronological age alone concerning a person's physical and psychological well-being. In fact, disease, physical fitness, social networking, stable partnership, and life situation play a crucial role in the incidence of complications. Instead, however, when it comes to late motherhood, age is associated in critical accounts in an undifferentiated way with morbidity and psychological instability and is thus used in a discriminatory way. A straightforward medical and ethical evaluation of late motherhood that takes a homogeneous group of "old women" as its point of departure does not do justice to individual variations in life situations. In this respect, age as a predictor of risk in the debate about SF is, from an ethical point of view, an empty concept based on gender stereotypes and discriminatory connotations of aging. Therefore, legal limits for the age of implantation of embryos following oocyte cryopreservation should not be stipulated either.

\section{Acknowledgements}

Translated by Ciaran Cronin for SocioTrans-Social Science Translation \& Editing Services. We are grateful to three anonymous reviewers for helpful comments.

\section{Author Contributions}

The research presented in this paper is part of Stephanie Bernstein's dissertation on the ethics of "social freezing" under the supervision of Claudia Wiesemann. Both authors were involved in developing the concept of the paper, writing, and revising it.

\section{Conflicts of Interest}

The authors declare no conflict of interest. 


\section{References}

1. Sobotka, Tomáš. "Mutterschaft in fortgeschrittenem Alter: Eine überfällige 'Revolution'?" Journal für Generationengerechtigkeit 9 (2009): 63-68. (In German)

2. European Commission. Demography Report 2010. Older, More Numerous and Diverse Europeans. Luxembourg: Publications Office of the European Union, 2011.

3. Statistisches Bundesamt. "Lebenserwartung." Available online: https://www.destatis.de/DE/ ZahlenFakten/GesellschaftStaat/Bevoelkerung/Sterbefaelle/Tabellen/LebenserwartungBundeslaen derWeiblich.html (accessed on 10 March 2014).

4. Berlin-Institut für Bevölkerung und Entwicklung. Die demografische Lage der Nation: Wie zukunftsfähig sind Deutschlands Regionen? München: Deutscher Taschenbuch Verlag, 2006, pp. 32-35. (In German)

5. Gook, Debra A. "History of oocyte cryopreservation." Reproductive BioMedicine Online 23 (2011): 281-89.

6. Rienzi, Laura, Stefania Romano, Laura Albricci, Roberto Maggiulli, Antonio Capalbo, Elena Baroni, Silvia Colamaria, Fabio Sapienza, and Filippo Ubaldi. "Embryo development of fresh 'versus' vitrified metaphase II oocytes after ICSI: A prospective randomized sibling-oocyte study." Human Reproduction 25 (2009): 66-73.

7. Cobo, Ana, Marcos Meseguer, José Remohi, and Antonio Pellicer. "Use of cryo-banked oocytes in an ovum donation programme: A prospective, randomized, controlled, clinical trial." Human Reproduction 25 (2010): 2239-46.

8. "Danish Artificial Fertilisation Act." Available online: https://www.retsinformation.dk/ print.aspx?id=10319\&exp=1 (accessed on 12 March 2014) (only Danish version available).

9. Edgar, David H., and Debra A. Gook. "A critical appraisal of cryopreservation (slow cooling versus vitrification) of human oocytes and embryos." Human Reproduction Update 18 (2012): 536-54.

10. Noyes, Nicole, Jeffrey Boldt, and Zsolt P. Nagy. "Oocyte cryopreservation: Is it time to remove its experimental label?" Journal of Assisted Reproduction and Genetics 27 (2010): 69-74.

11. Smith, Gary D., Paulo C. Serafini, Joyce Fioravanti, Isaac Yadid, Marcio Coslovsky, Pericles Hassun, José R. Alegretti, and Eduardo L. Motta. "Prospective randomized comparison of human oocyte cryopreservation with slow-rate freezing or vitrification." Fertility and Sterility 94 (2010): 2088-95.

12. Sousa, Mário, Mariana Cunha, Paulo Viana, Joaquina Silva, José T. Silva, Cristiano Oliveira, and Alberto Barros. "Outcomes of human blastocyst transfer after slow-freezing using sequential culture: A clinical report." Archives of Gynecology and Obstetrics 285 (2012): 1473-78.

13. Solé, Miguel, Josep Santaló, Merce Boada, Elisabet Clua, Ignacio Rodríguez, Francisca. Martinez, Buenaventura Coroleu, Pedro N. Barri, and Anna Veiga. "How does vitrification affect oocyte viability in oocyte donation cycles? A prospective study to compare outcomes achieved with fresh versus vitrified sibling oocytes." Human Reproduction 28 (2013): 2087-92.

14. Fadini, Rubens, Mario Mignini Renzini, Mariabeatrice Dal Canto, Amalia Epis, Marilena Crippa, Ilaria Caliari, Claudio Brigante, and Giovanni Coticchio. "Oocyte in vitro maturation in normo-ovulatory women.” Fertility and Sterility 99 (2013): 1162-69. 
15. Darnovsky, Marcy. "Egg Freezing: Risks to Women and Children Unknown.” Biopolitical Times, 29 August 2011. Available online: http://www.biopoliticaltimes.org/article.php?id=5833 (accessed on 4 November 2013).

16. Bittner, Uta, and Oliver Müller. "Technisierung der Lebensführung: Zur ethischen Legitimität des Einfrierens von Eizellen bei gesunden Frauen als Instrument der Familienplanung.” In Jahrbuch für Wissenschaft und Ethik. Edited by Ludger Honnefelder and Dieter Sturma. Berlin: de Gruyter, 2010, pp. 23-45. (In German)

17. DIR Deutsches IVF-Register. "Jahrbuch 2011." Journal für Reproduktionsmedizin und Endokrinologie 9 (2012): 453-84. (In German)

18. Coticchio, Giovanni. "Vitrification may increase the rate of chromosome misalignment in the metaphase II spindle of human mature oocytes." Reproductive BioMedicine Online 19 (2009): 29-34.

19. Sharma, Rakesh K., Ali Azeem, and Ashok Agarwal. "Spindle and Chromosomal Alterations in Metaphase II Oocytes.” Reproductive Sciences 20 (2013): 1293-301.

20. Cobo, Ana, Juan A. Garcia-Velasco, Javier Domingo, José Remohí, and Antonio Pellicer. "Is vitrification of oocytes useful for fertility preservation for age-related fertility decline and in cancer patients?" Fertility and Sterility 99 (2013): 1485-95.

21. Nawroth, Frank, Ralf Dittrich, Markus Kupka, Barbara Lawrenz, Markus Montag, Michael von Wolff. "Kryokonservierung von unbefruchteten Eizellen bei nichtmedizinischen Indikationen (,social freezing“): Aktueller Stand und Stellungnahme des Netzwerkes FertiPROTEKT.” Frauenarzt 53 (2012): 528-33. (In German)

22. Cobo, Ana, and César Diaz. "Clinical application of oocyte vitrification: A systematic review and meta-analysis of randomized controlled trials." Fertility and Sterility 96 (2011): 277-85.

23. Antinori, Monica. "Cryotop vitrification of human oocytes results in high survival rate and healthy deliveries." Reproductive BioMedicine Online 14 (2007): 73-79.

24. Cobo, Ana, Masashigue Kuwayama, Sonia Pérez, Amparo Ruiz, Antonio Pellicer, and José Remohí. "Comparison of concomitant outcome achieved with fresh and cryopreserved donor oocytes vitrified by the Cryotop method." Fertility and Sterility 89 (2008): 1657-64.

25. Forman, Eric J., Li Xinying, Kathleen M. Ferry, Katherine Scott, Nathan R. Treff, and Richard T. Scott. "Oocyte vitrification does not increase the risk of embryonic aneuploidy or diminish the implantation potential of blastocysts created after intracytoplasmic sperm injection: A novel, paired randomized controlled trial using DNA fingerprinting." Fertility and Sterility 98 (2012): 644-49.

26. Pegg, David E. "The role of vitrification techniques of cryopreservation in reproductive medicine." Human Fertility 8 (2005): 231-39.

27. Khalili, Mohammad Ali., Michela Maione, Maria Grazia Palmerini, Stefano Bianchi, Guido Macchiarelli, and Stefania Annarita Nottola. "Ultrastructure of human mature oocytes after vitrification." European Journal of Histochemistry 56 (2012): 236-42.

28. Seet, V. Y. K., S. Al-Samerria, Jesmine Wong, James Stanger, John L. Yovich, and Ghanim Almahbobi. "Optimising vitrification of human oocytes using multiple cryoprotectants and morphological and functional assessment." Reproduction, Fertility and Development 25 (2013): 918-26.

29. Berthelot-Ricou, Anais, Jeanne Perrin, Carole Di Giorgio, Michel de Meo, Alain Botta, and Blandine Courbiere. "Genotoxicity assessment of mouse oocytes by comet assay before 
vitrification and after warming with three vitrification protocols." Fertility and Sterility 100 (2013): 882-88.

30. Benson, James D., Carmen C. Chicone, and John K. Critser. "Analytical Optimal Controls for the State Constrained Addition and Removal of Cryoprotective Agents." Bulletin of Mathematical Biology 74 (2012): 1516-30.

31. Bielanski, Andrzej, and Gabor Vajta. "Risk of contamination of germplasm during cryopreservation and cryobanking in IVF units." Human Reproduction 24 (2009): 2457-67.

32. The Practice Committee of the American Society for Reproductive Medicine, and the Practice Committee of the Society for Assisted Reproductive Technology. "Ovarian tissue and oocyte cryopreservation." Fertility and Sterility 90 (2008): 241-46.

33. The Practice Committee of the American Society for Reproductive Medicine, and the Practice Committee of the Society for Assisted Reproductive Technology. "Essential elements of informed consent for elective oocyte cryopreservation: A Practice Committee opinion." Fertility and Sterility 90 (2008): 134-35.

34. Tur-Kaspa, Ilan, Michael Gal, and Allan Horwitz. "Genetics and health of children born from cryopreserved oocytes." Fertility and Sterility 88 (2007): S14. Paper presented at ASRM 63rd Annual Meeting, Washington, DC, USA, 13 to 17 October 2007.

35. Chian, Ri-Cheng, Jack Y. Huang, Seang L. Tan, Elkin Lucena, Angela Saa, Alejandro Rojas, Luis Arturo Ruvalcaba Castellón, Martha Isolina García Amador, and Jorge Eduardo Montoya Sarmiento. "Obstetric and perinatal outcome in 200 infants conceived from vitrified oocytes." Reproductive BioMedicine Online 16 (2008): 608-10.

36. Noyes, Nicole. "Over 900 oocyte cryopreservation babies born with no apparent increase in congenital anomalies." Reproductive BioMedicine Online 18 (2009): 769-76.

37. Wikland, Matts, Thorir Hardarson, Torbjörn Hillensjo, Cecilia Westin, Göran Westlander, Margareta Wood, and Ulla-Britt Wennerholm. "Obstetric outcomes after transfer of vitrified blastocysts." Human Reproduction 25 (2010): 1699-707.

38. Queißer-Luft, Annette, and Jürgen Spranger. "Fehlbildungen bei Neugeborenen." Deutsches Ärzteblatt 103 (2006): 2464-71. (In German)

39. Belva, Florence, Stefanie Henriet, Etienne van den Abbeel, Michel Camus, Paul Devroey, Josianna van der Elst, Inge Liebaers, Patrick Haentjens, and Maryse Bonduelle. "Neonatal outcome of 937 children born after transfer of cryopreserved embryos obtained by ICSI and IVF and comparison with outcome data of fresh ICSI and IVF cycles." Human Reproduction 23 (2008): 2227-38.

40. The Practice Committee of the American Society for Reproductive Medicine, and the Practice Committee of the Society for Assisted Reproductive Technology. "Mature oocyte cryopreservation: A guideline." Fertility and Sterility 99 (2013): 37-43.

41. Gerhard, Ingrid, and Axel Feige, eds. Geburtshilfe integrativ: Konventionelle und komplementäre Therapie. Munich: Elsevier, 2005.

42. Balasch, Juan, and Eduard Gratacós. "Delayed childbearing." Current Opinion in Obstetrics and Gynecology 24 (2012): 187-93. 
43. Cleary-Goldman, Jane, Fergal D. Malone, John Vidaver, Robert H. Ball, David A. Nyberg, Christine H. Comstock, George R. Saade, Keith A. Eddleman, Susan Klugman, Lorraine Dugoff et al. "Impact of Maternal Age on Obstetric Outcome." Obstetrics \& Gynecology 105 (2005): 983-90.

44. Glasser, Saralee, Aliza Segev-Zahav, Paige Fortinsky, Debby Gedal-Beer, Eyal Schiff, and Liat Lerner-Geva. "Primiparity at Very Advanced Maternal Age ( $\geq 45$ years)." Fertility and Sterility 95 (2011): 2548-51.

45. Jacobsson, Bo, Lars Ladfors, and Ian Milsom. "Advanced Maternal Age and Adverse Perinatal Outcome.” Obstetrics \& Gynecology 104 (2004): 727-33.

46. Kenny, Louise C., Tina Lavender, Roseanne McNamee, Sinéad M. O’Neill, Tracey Mills, Ali S. Khashan, and Qinghua Shi. "Advanced Maternal Age and Adverse Pregnancy Outcome: Evidence from a Large Contemporary Cohort.” PLoS ONE 8 (2013): e56583.

47. Ritzinger, Petra, Joachim W. Dudenhausen, and Wolfgang Holzgreve. "Späte Mutterschaft und deren Risiken.” Journal für Reproduktionsmedizin und Endokrinologie 8 (2011): 112-22. (In German)

48. Schmidt, Lone, Tomáš Sobotka, Janne Gasseholm Bentzen, and A. Nyboe Andersen. "Demographic and medical consequences of the postponement of parenthood." Human Reproduction Update 18 (2011): 29-43.

49. Yogev, Yariv, Nir Melamed, Ron Bardin, Kinneret Tenenbaum-Gavish, Gadi Ben-Shitrit, and Avi Ben-Haroush. "Pregnancy outcome at extremely advanced maternal age." American Journal of Obstetrics and Gynecology 203 (2010): 558.e1-7.

50. Dulitzki, Mordechai, David Soriano, Eyal Schiff, Angela Chetrit, Shlomo Mashiach, and Daniel S. Seidman. "Effect of Very Advanced Maternal Age on Pregnancy Outcome and Rate of Cesarean Delivery." Obstetrics \& Gynecology 92 (1998): 935-39.

51. Favilli, Alessandro, Silvia Pericoli, Marta M. Acanfora, Vittorio Bini, Di Renzo, Gian Carlo, and Sandro Gerli. "Pregnancy outcome in women aged 40 years or more." Journal of Maternal-Fetal and Neonatal Medicine 25 (2012): 1260-63.

52. Paulson, Richard J., Robert Boostanfar, Peyman Saadat, Eliran Mor, David E. Tourgeman, Cristin C. Slater, Mary M. Francis, and John K. Jain. "Pregnancy in the Sixth Decade of Life: Obstetric Outcomes in Women of Advanced Reproductive Age." Journal of the American Medical Association 288 (2002): 2320-23.

53. Sauer, Mark V., Richard J. Paulson, and Rogerio A. Lobo. "Oocyte donation to women of advanced reproductive age: Pregnancy results and obstetrical outcomes in patients 45 years and older." Human Reproduction 11 (1996): 2540-43.

54. Bateman, Brian T., and Lynn L. Simpson. "Higher rate of stillbirth at the extremes of reproductive age: A large nationwide sample of deliveries in the United States." American Journal of Obstetrics and Gynecology 194 (2006): 840-45.

55. Fretts, Ruth C. "Etiology and prevention of stillbirth." American Journal of Obstetrics and Gynecology 193 (2005): 1923-35.

56. Huang, Ling, Reg Sauve, Nick Birkett, Dean A. Fergusson, and Carl van Walraven. "Maternal age and risk of stillbirth: A systematic review." Canadian Medical Association Journal 178 (2008): 165-72.

57. Silver, Robert M. “Fetal Death.” Obstetrics \& Gynecology 109 (2007): 153-67. 
58. Peters, Frederik. "Späte Mutterschaft als medizinischer Risikofaktor? Der Einfluss des Alters der Mutter auf das Risiko der Frühgeburt." SOEPpapers at DIW Berlin 342 (2010): 1-49. (In German)

59. Shkedi-Rafid, Shiri, and Yael Hashiloni-Dolev. "Egg freezing for non-medical uses: The lack of a relational approach to autonomy in the new Israeli policy and in academic discussion." Journal of Medical Ethics 38 (2012): 154-57.

60. Pennings, Guido. "Postmenopausal Women and the Right of Access to Oocyte Donation." Journal of Applied Philosophy 18 (2001): 171-81.

61. Parks, Jennifer A. “On the Use of IVF by Post-menopausal Women." Hypatia 14 (1999): 77-96.

62. Smajdor, Anna. "The ethics of egg donation in the over fifties." Menopause international 14 (2008): 173-77.

63. Nilsen, Anne Britt Vika, Ulla Waldenström, Anna Hjelmsted, Svein Rasmussen, and Erica Schytt. "Characteristics of women who are pregnant with their first baby at an advanced age." Acta Obstetricia et Gynecologica Scandinavica 91 (2012): 353-62.

64. Renner, Ilona, and Anneliese Hendel-Kramer. "Schwangere Frauen ab 35. Eine Zielgruppe mit besonderem Unterstützungsbedarf?” BZgA FORUM (2008): 28-34. (In German)

65. Steiner, Anne Z., and Richard J. Paulson. "Motherhood after age 50: An evaluation of parenting stress and physical functioning." Fertility and Sterility 87 (2007): 1327-32.

66. McLeod, Carolyn, and Susan Sherwin. "Relational Autonomy, Self-trust, and Health Care for patients who are oppressed." In Relational Autonomy: Feminist Perspectives on Autonomy, Agency, and the Social Self. Edited by Catriona Mackenzie and Natalie Stoljar. New York: Oxford University Press, 1999, pp. 259-79.

67. Harwood, Karey. "Egg Freezing: A Breakthrough for Reproductive Autonomy?" Bioethics 23 (2009): 39-46.

68. Wirleitner, Barbara, Pierre Vanderzwalmen, Magnus Bach, Batsuren Baramsai, Anton Neyer, Delf Schwerda, Maximilian Schuff, Dietmar Spitzer, Astrid Stecher, Martin Zintz et al. "The time aspect in storing vitrified blastocysts: Its impact on survival rate, implantation potential and babies born." Human Reproduction 28 (2013): 2950-57.

69. Hassold, Terry, and Patricia Hunt. "Maternal age and chromosomally abnormal pregnancies: What we know and what we wish we knew." Current Opinion in Pediatrics 21 (2009): 703-08.

70. Liu, Kimberly, and Allison Case. "Advanced Reproductive Age and Fertility." Journal of Obstetrics and Gynaecology Canada (2011): 1165-75.

71. Nelson, Scott M., Evelyn E. Telfer, and Richard A. Anderson. "The ageing ovary and uterus: New biological insights.” Human Reproduction Update 19 (2012): 67-83.

72. Kort, Daniel, Jennifer Gosselin, Janet Choi, Melvin Thornton, Jane Cleary-Goldman, and Mark Sauer. "Pregnancy after Age 50: Defining Risks for Mother and Child." American Journal of Perinatology 29 (2012): 245-50.

73. Sauer, Mark V. "Reversing the Natural Decline in Human Fertility." Journal of the American Medical Association 268 (1992): 1270-75.

74. Mertes, Heidi, and Guido Pennings. "Social egg freezing: For better, not for worse." Reproductive BioMedicine Online 23 (2011): 824-29.

75. Rybak, Eli A., and Harry J. Lieman. "Egg freezing, procreative liberty, and ICSI: The double standards confronting elective self-donation of oocytes." Fertility and Sterility 92 (2009): 1509-12. 
76. Human Fertilisation and Embryology Authority. "Fertility Treatment in 2012: Trends and figures." Available online: http://www.hfea.gov.uk/docs/FertilityTreatment2012TrendsFigures.PDF (accessed on 28 April 2014).

77. Dondorp, Wybo J., and Guido M.W.R de Wert. "Fertility preservation for healthy women: Ethical aspects." Human Reproduction 24 (2009): 1779-85.

78. Goold, Imogen, and Julian Savulescu. "In Favour of Freezing Eggs for Non-Medical Reasons." Bioethics 23 (2009): 47-58.

79. Petropanagos, Angel. "Reproductive 'Choice' and Egg Freezing." In Cancer Treatment and Research: Oncofertility. Edited by Teresa K. Woodruff, Laurie Zoloth, Lisa Campo-Engelstein and Sarah Rodriguez. Boston: Springer US, 2010, pp. 223-35.

80. Petropanagos, Angel. "Fertility Preservation Technologies for Women: A Feminist Ethical Analysis.” Ph.D. Dissertation, University of Western Ontario, 2013.

81. Maura Kelly. "Women's Voluntary Childlessness: A Radical Rejection of Motherhood?" WSQ: Women's Studies Quarterly 37 (2010): 157-72.

82. Gillespie, Rosemary. "Voluntary Childlessness in the United Kingdom." Reproductive Health Matters 7 (1999): 43-53.

83. Alsop, Rachel, Annette Fitzsimons, and Kathleen Lennon. Theorizing Gender. Malden: Blackwell, 2002.

84. Bozzaro, Claudia. "Ein Kind ja, aber erst irgendwann...: Überlegungen zum Einsatz von Egg- und Ovarian Tissue Freezing." In Kinderwunsch und Reproduktionsmedizin: Ethische Herausforderungen der technisierten Fortpflanzung. Edited by Giovanni Maio, Tobias Eichinger and Claudia Bozzaro. München: Alber, 2013, pp. 233-49. (In German)

85. Benson, Paul. "Feminist Intuitions and the Normative Substance of Autonomy." In Personal Autonomy: New Essays on Personal Autonomy and Its Role in Contemporary Moral Philosophy. Edited by James S. Taylor. Cambridge, UK: Cambridge University Press, 2008, pp. 124-42.

86. Stoop, Dominic, Julie Nekkebroeck, and Paul Devroey. "A survey on the intentions and attitudes towards oocyte cryopreservation for non-medical reasons among women of reproductive age." Human Reproduction 26 (2011): 655-61.

87. Lockwood, Gillian M. "Social egg freezing: The prospect of reproductive 'immortality' or a dangerous delusion?" Reproductive BioMedicine Online 23 (2011): 334-40.

88. Birnbacher, Dieter. Natürlichkeit. Berlin: De Gruyter, 2006. (In German)

89. Goold, Imogen. "Should older and postmenopausal women have access to assisted reproductive technology?" Monash Bioethics Review 24 (2005): 27-46.

90. Bray, Isabelle, and David Gunnell. "Advanced paternal age: How old is too old?" Journal of Epidemiology \& Community Health 60 (2006): 851-53.

91. Sartorius, Gideon A., and Eberhard Nieschlag. "Paternal age and reproduction." Human Reproduction Update 16 (2009): 65-79.

(C) 2014 by the authors; licensee MDPI, Basel, Switzerland. This article is an open access article distributed under the terms and conditions of the Creative Commons Attribution license (http://creativecommons.org/licenses/by/3.0/). 